\title{
Investigation of Critical Characteristics of Mineral Oil with Activated Carbon
}

\author{
M. Vanitha', N. Narmadhai' ${ }^{2}$, M. Karthik ${ }^{1}$ \\ ${ }^{1}$ Department of Electrical and Electronics Engineering, Coimbatore Institute of Engineering and Technology, \\ Coimbatore, India \\ ${ }^{2}$ Department of Electrical Engineering, Government College of Technology, Coimbatore, India \\ Email:vaniarun13@gmail.com,narmadhai@gct.ac.in, kartik.m1992@gmail.com
}

Received 6 May 2016; accepted 15 May 2016; published 27 July 2016

Copyright (C) 2016 by authors and Scientific Research Publishing Inc.

This work is licensed under the Creative Commons Attribution International License (CC BY).

http://creativecommons.org/licenses/by/4.0/

(c)

\section{Abstract}

Fluid insulating medium is used for electrical insulation and provides a cooling medium in high voltage power transformers. Due to this reason, petroleum based mineral oil (transformer oil) is mostly used for a number of years which holds the benefit of cost effectiveness and good flow rate. This benefit leads to more requirements of oil that may cause oil scarcity in the near future. In order to overcome the scarcity in forthcoming years many research works focus on identifying the best approach for regeneration of oils. In this paper, activated carbon obtained from the agricultural waste is used which acts as the absorbent of impurities. Use of activated carbon is a perfect approach for regeneration of oils. Critical characteristics such as breakdown voltage, flash point, fire point and viscosity are measured for the pure and aged mineral oil with and without adding activated carbon. By this approach it is found that the activated carbon with used oil 1, used oil 2 and fresh oil provides continuous improvement of properties as per IEC (International Electrotechnical Commission) and ASTM (American Society for Testing and Materials) standards which will reduce the oil consumption and cost. From the analysis, it reveals that mineral oil with activated carbon has better properties and the use of activated carbon is the best practice of regeneration of oils.

\section{Keywords}

Activated Carbon, Mineral Oil, Power Transformer, Breakdown Voltage, Viscosity

\section{Introduction}

Transformer life management is an essential part of modern power operation system. Oil filled technology has 
been used for more than 100 years. The principle of operation has not changed over many decades. Properly maintained power transformers can function for 50 to 75 years [1] [2]. The life of transformer mainly depends on insulating medium. The insulation medium used in transformer is classified into three categories, such as solid, liquid and gas. Among them solid and liquid insulations are mostly used.

Transformer oil is a highly refined mineral oil that is stable at high temperatures. It is utilized as a liquid insulation by oil filled transformers, high voltage capacitors, high voltage switches and circuit breakers due to its excellent electrical insulating properties. Its major role is to insulate, suppress corona and arcing, and to serve as a coolant. Under operating conditions, the transformer oil is subjected to electrical, mechanical and thermal stresses.

At higher temperatures, chemical interactions of windings and solid insulation catalyzation cause contamination. Chemical properties of transformer oil are altered, making it ineffective for its indented purpose. In large transformers, periodic testing of oil is done for its electrical and chemical properties. There is a long standing, proven, track record of the performance and low costs. It is important to define that mineral oil shows its better performance under sealed condition. Mineral oil is acquired using fractional distillation and continuous treatment of crude petroleum products and it has the intricate mixtures of various natural compounds which has different structures of carbon and hydrogen molecules.

For more than 100 years, a derivative of petroleum product is used as liquid insulation which is known as mineral oil or transformer oil. In some special applications, some other liquid insulations such as silicone oil, synthetic hydrocarbon and etc., are used in the transformers. But these oils are costlier than mineral oil [3]-[6]. Usually the life \& performance of transformer is analyzed by the liquid and solid insulation in which the quality of solid insulation mainly depends on the liquid insulation. If the oil quality is as per the standards (which are free from impurities) then the solid insulation is not affected by the oil. In other case if the quality of the oil does not satisfy the standards the oil affects the solid insulation and also the inner windings.

Mineral oil is used for two purposes, it helps to preserve the core and windings and another important purpose of this oil is to prevent direct contact of atmospheric oxygen with cellulose made [7]. In several decades many researches are done in this field to provide the enhanced samples to increase the properties and efficiency of transformer applications.

Since the mineral oil has good flow rate and low cost, it is mostly used in power transformer application but the incessant use of mineral oil may cause oil scarcity in the near future so it is very much essential to find the regeneration of oil without dropping its properties [8].

\section{Current Efforts}

High quantity transformer oil is required to increase the reliability and the life time of the transformer. The transformer oil properties should be monitored in order to give early warnings and maintain the efficiency. In order to increase the life time of transformer the quality of oil must be checked periodically. The sample of oil is collected from the transformer and tested. Based on the obtained results it is decided whether the oil has to be changed or it should be either replaced or regenerated. If the oil has more impurities then the oil is unsuitable for transformer application and if the unsuitable oils are used for a long time the oil will affect the solid insulation of the transformer which will lead to serious damages and finally the replacement becomes costly. The presence of metal impurities and products of oil oxidation renders the oil unsuitable for application, and therefore oils are usually replaced with fresh ones at regular basis. In this paper the periodical replacement of oil is put back by the idea of recycling the used oil with chemical additives. In this work activated carbon is used as a chemical additive which is blended with the oil for enhancing the efficiency of transformer life. The used oil generally contains large proportions of valuable base oil which can be reused if adverse pollutants are removed. The regeneration of transformer oil is conventionally carried out using the adsorption process, which consist of the removal of acid components, water and oxidation products with an adsorbent. Hence activated carbon is used for regenerating the oil without dropping its property. This idea is found to be cost effective and the usage of regenerated oil with additives decreases the oil usage which will reduce the future oil paucity.

\section{Activated Carbon}

Activated carbon is also called as activated charcoal or carbon activates. It is in the form of carbon that has been processed to make it extremely porous and thus it has a very large surface area available for adsorption or 
chemical reaction. Activated carbon has been used to purify different products since roman times [9] [10]. Carbon treatment is primarily based on a naturally occurring phenomenon called absorption, in which molecules of a liquid or gas are trapped by either an external or internal surface of a solid. The phenomenon is somewhat similar to iron fillings held by the magnet. Activated carbon has a random number of graphite platelets. The force that fixes the products to be absorbed is called the London dispersion force. The London dispersion force is very strong but only over short distances. It is equal between all carbon atoms and is not dependent on outside parameters such as temperature and pressure [11]. When considering this, it is clear that the absorbate molecules will be held most strongly where they are surrounded by the most carbon atoms.

Activated carbon can be considered as a material of phenomenal surface area made up of millions of pores relatively like a "molecular sponge" [12]. The process by that such a surface concentrates fluid molecules by chemical and/or physical forces is thought as sorption (whereas, absorption is a process whereby fluid molecules are concerned by a liquid or solid and distributed throughout that liquid or solid). In the physical adsorption method, molecules are command by the carbon's surface by weak forces renowned as Van Der Waals Forces ensuing from building block attraction [13]. The carbon and the absorbate are therefore unchanged with chemicals. However, in the process referred to as chemosorption molecules with chemicals react with the carbon's surface (or AN impregnate on the carbon's surface) and are command by a lot of stronger forces chemical bonds.

\section{Sample Description}

The high quality traditional mineral oil and aged mineral oil are used for investigation. The aged mineral oil at different ageing period is taken and it is named as (Used Transformer Oil) U1 (20 hrs aged) and U2 (40 hrs aged). The fresh mineral oil is named as FTO (Fresh Transformer Oil). The critical characteristics are measured with and without adding activated carbon in both pure and aged mineral oil. The activated carbon is blended with the oil samples in two proportions such as 5 gram and 10 gram (minimum and maximum ratio). The oil samples U1, U2, FTO before \& after blending (AB) activated carbon is shown in Figures 1-3.

A $500 \mathrm{ml}$ of oil is collected in a beaker which is used for preparation of testing samples. The sample is heated with the help of heating chamber to a temperature required to dissolve additive compounds. The test samples are produced by adding additive compounds to the oil in various proportions such as $5 \mathrm{gm}$ and $10 \mathrm{gm}$. The heating

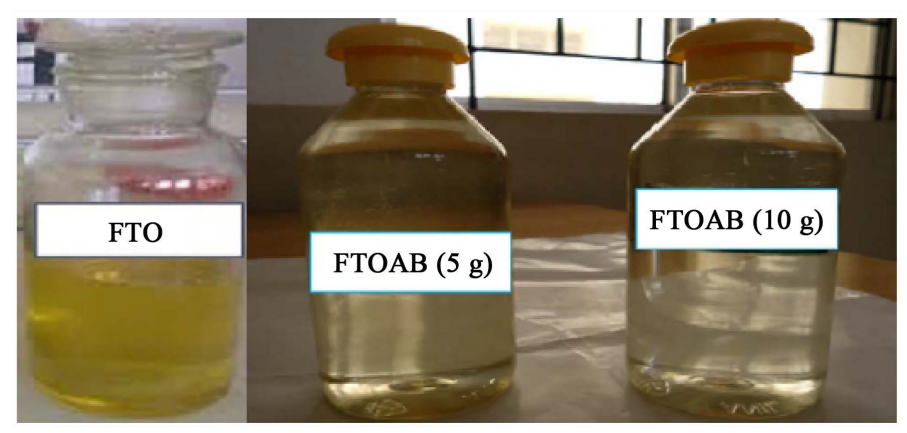

Figure 1. Fresh transformer oil before and after blending (AB).

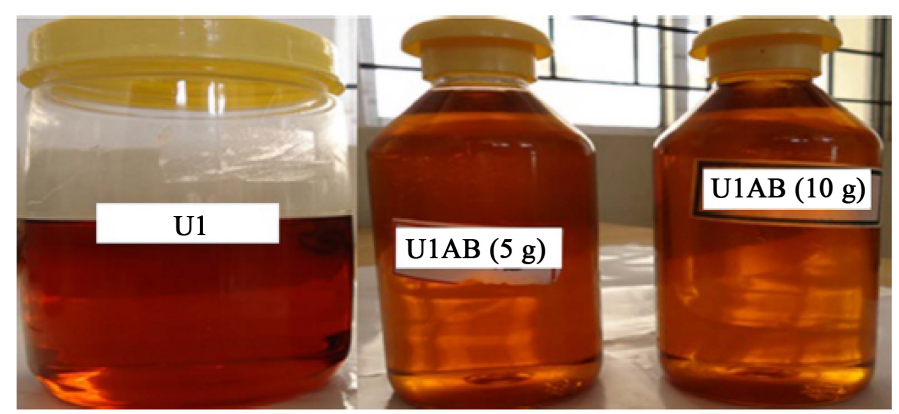

Figure 2. Used transformer oil 1 before and after blending (AB). 
chamber arrangement and the magnetic stirrer is shown in Figure 4 \& Figure 5. The temperature should be maintained until the additive compounds dissolve completely in the fluids. These fluids are then subjected to a magnetic stirrer with 450 to 500 rpm (rotations per minute) for 30 minutes for equivalent dispersion of additives in fluids by maintaining the temperature of a fluid and speed of stirrer constant throughout the blending process. Then the fluids are stored in a storage container for testing purpose.

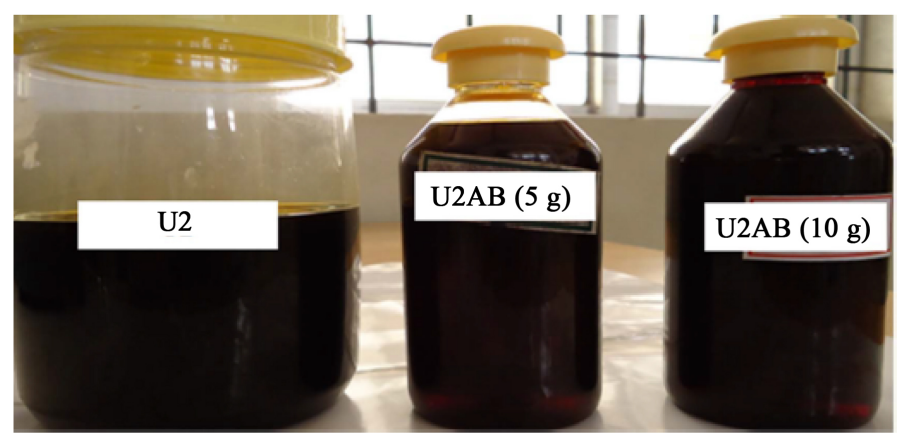

Figure 3. Used Transformer Oil 2 before and after blending (AB).

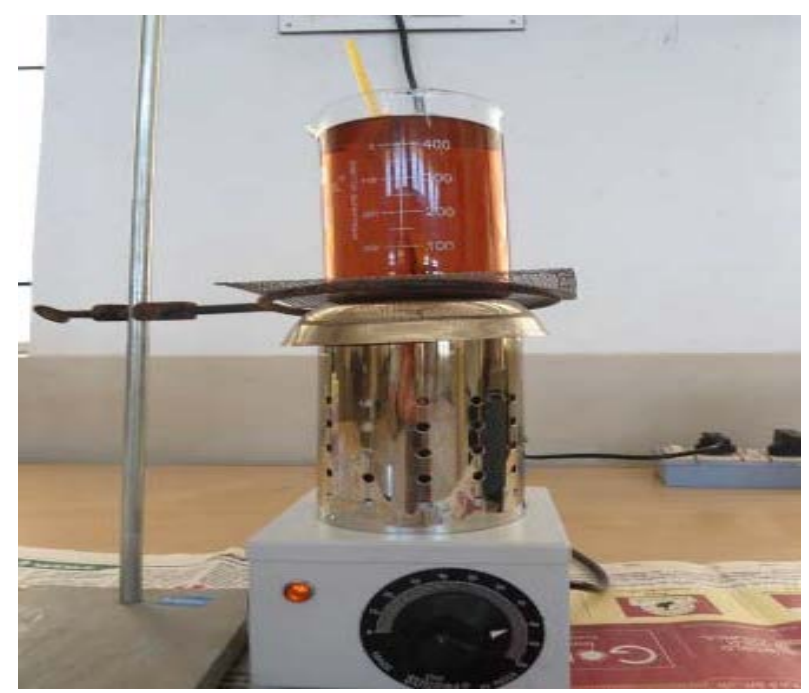

Figure 4. Heating chamber arrangement.

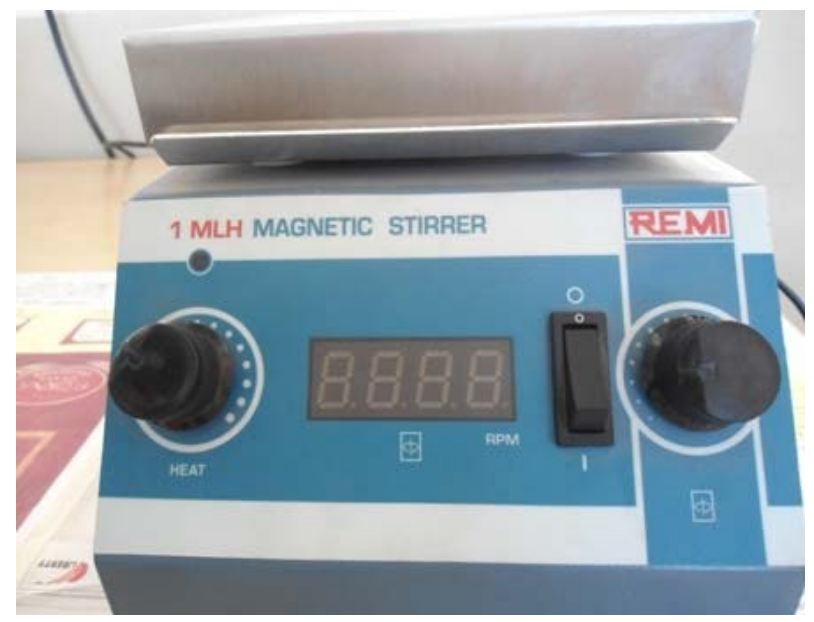

Figure 5. Magnetic stirrer. 


\section{Experimental Methodology}

Oil Properties such as breakdown voltage, flash point, fire point, viscosity are measured with and without adding the additives with the help of the setups shown in Figures 6-8 and it is compared with the international standard values described in Table 1 for analyzing the suitability [14].

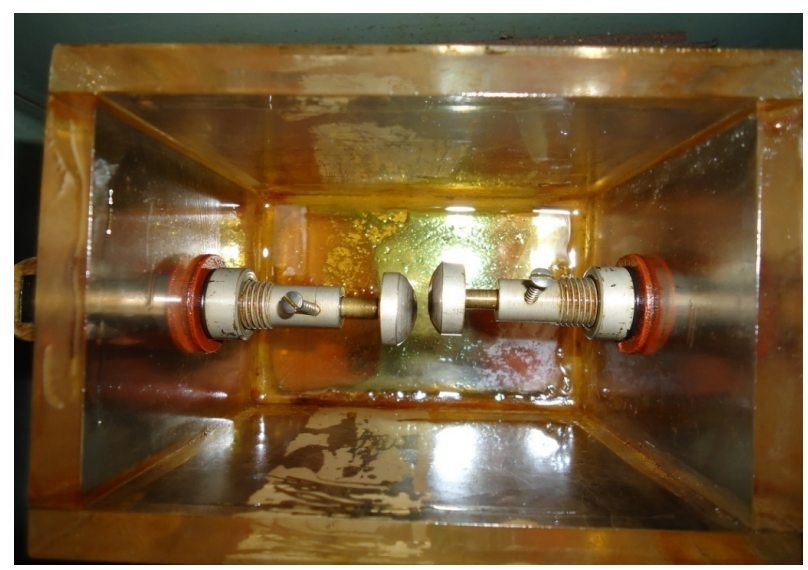

Figure 6. Breakdown voltage testing electrodes.

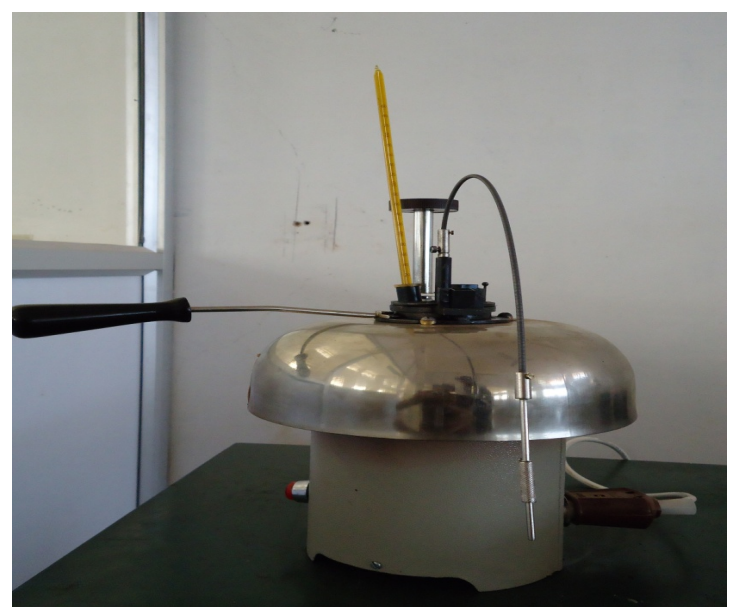

Figure 7. Flash and fire point setup.

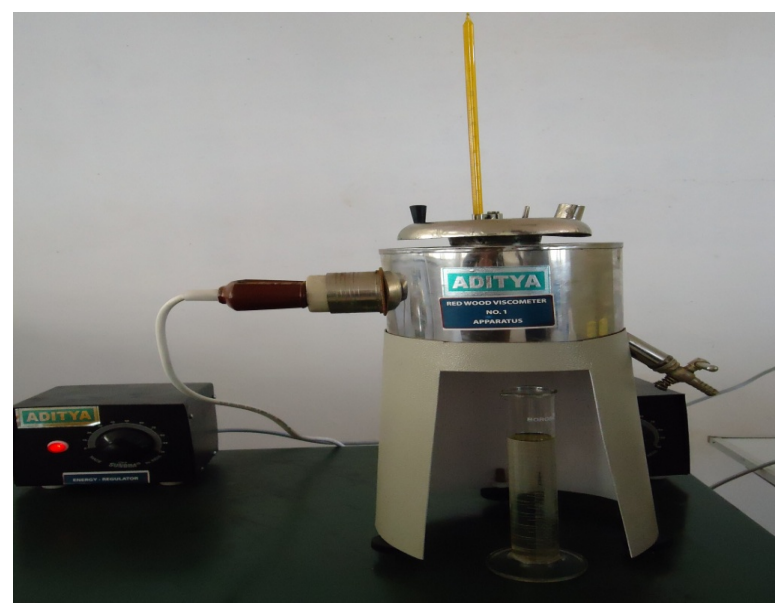

Figure 8. Karl Fischer viscosity meter. 
Table 1. Standard for characteristics of insulating fluids.

\begin{tabular}{cccc}
\hline Parameters & Breakdown voltage $(\mathrm{kV})$ & Flash Point \& Fire point $\left({ }^{\circ} \mathrm{C}\right)$ & Viscosity $(\mathrm{cst})$ \\
\hline Standards for insulating fluids & IEC 60156 & ASTM D93 & ASTM D445 \\
Range & $>30 \mathrm{kV}$ & Min. $135^{\circ} \mathrm{C}$ & Max. $12 \mathrm{~mm}^{2} / \mathrm{s}$ \\
\hline
\end{tabular}

\subsection{Breakdown Voltage}

Breakdown voltage of liquid insulation determines the ability to be a perfect insulation. This property mainly depends on oil purity. In case of any presence of contaminants or moisture in oil, value of breakdown voltage will reduce [14] [15]. For measurement of breakdown voltage, IEC 60156 standards is used [16] [17]. The oil sample whose breakdown voltage is to be determined is filled in the test cell and placed in the breakdown voltage kit with $2.5 \mathrm{~mm}$ gapped spherical electrodes shown in Figure 6. In the rate of $2 \mathrm{kV} / \mathrm{s}$, the input voltage to test cell was varied until the breakdown of oil is identified, this method is done for consecutive five times for the accurate result and breakdown voltage was calculated by taking average of five consecutive breakdown tests for the same sample. As per standard requirement of new insulating oil, the breakdown voltage should be greater than $30 \mathrm{kV}$. Breakdown voltages of oil samples are tabulated in Tables 2-4 and the graphical representation is shown in Figure 9.

\subsection{Flash Point and Fire Point}

Flammability characteristic of liquid insulation is analyzed with help of measurement of flash point and fire point. Higher flash point indicates low flammability of oil [14]. Flash point and fire point measurement was conducted according to the standard ASTM D93 [18]. The Pensky Martins Flash point setup is shown in Figure 7. İn Pensky Martin apparatus $60 \mathrm{ml}$ of oil sample was taken in a chamber and heated using the regulator power supply by which the supply can be varied. This setup consists of coil which is used to heat the test chamber in which the oil is filled. The test chamber has the lid, test opening and the holder to place a thermometer. Flash point and fire point temperature was identified by introducing a test flame in test opening. Flash point and fire point was indicated by temporary flame and complete fire on oil surface receptively. Flash point and fire point temperatures for all oil samples are noted using the thermometer and the values are given in Tables 2-4 and the graphical representation is shown in Figure 10.

\subsection{Viscosity}

Viscosity of oil samples are indications of flow resistance of oil on smooth surface. Viscosity of insulating oil related with heat transfer ability of it. Oil with low viscosity has higher heat transfer capacity [14]. Viscosity is determined using karl fischer viscosity meter as shown in Figure 8. This viscosity meter consist of oil chamber where $50 \mathrm{ml}$ of oil is filled there is a vent in the bottom of the chamber which is closed using a iron strip. During the measurement the stop clock is kept ON and the strip is removed so that the oil starts to flow through the vent and it is collected in a beaker. Viscosity was measured according to the standard ASTM D445 [19]. Time taken for $50 \mathrm{ml}$ of oil to flow in Redwood viscometer was calculated. Viscosity of oil samples are calculated from that time. Viscosity of oil samples are tabulated in Tables 2-4 and the graphical representation is shown in Figure 11.

\section{Result and Discussion}

Generally, the breakdown voltage of insulating fluid should be high. The new oil posses high breakdown voltage and the aged oil posses low breakdown voltage which is mainly due to the impurities, water content and acidity that occurs in a oil due to oxidation. Table 2 and Table 3 clearly show that the used oil 1has low breakdown voltage of $28 \mathrm{kV}$ due to the carbon content which occurs by the breakdown of oil and the low breakdown voltage is further enhanced by adding activated carbon in various proportions. By adding 5 gm of activated carbon with used oil 1 the breakdown voltage is $30 \mathrm{kV}$ and by adding $10 \mathrm{gm}$ of activated carbon with used oil 1 the breakdown voltage is $34 \mathrm{kV}$. Similarly the used oil 2 has very low breakdown voltage of $20 \mathrm{kV}$ due to the impurities, water content and acidity. The low breakdown voltage is further enhanced by adding activated carbon in various proportions. By adding 5 gm of activated carbon with used oil 2 the breakdown voltage is 25 $\mathrm{kV}$ and by adding $10 \mathrm{gm}$ of activated carbon with used oil 2 the breakdown voltage is $32 \mathrm{kV}$. 
Table 2. Critical characteristics of U1 with and without adding activated carbon.

\begin{tabular}{ccccc}
\hline \multirow{2}{*}{ Parameters } & \multicolumn{3}{c}{ U1 Result } \\
\cline { 2 - 5 } & Breakdown voltage $(\mathrm{kV})$ & Flash Point $\left({ }^{\circ} \mathrm{C}\right)$ & Fire point $\left({ }^{\circ} \mathrm{C}\right)$ & Viscosity (cst) \\
\hline Without adding & 28 & 178 & 195 & 19.56 \\
$\mathrm{U} 1+5 \mathrm{gm}$ & 30 & 183 & 195 & 18 \\
$\mathrm{U} 1+10 \mathrm{gm}$ & 34 & 187 & 200 & 17 \\
\hline
\end{tabular}

Table 3. Critical characteristics of U2 with and without adding activated carbon.

\begin{tabular}{ccccc}
\hline \multirow{2}{*}{ Parameters } & \multicolumn{4}{c}{ U2 Result } \\
\cline { 2 - 5 } & Breakdown voltage $(\mathrm{kV})$ & Flash Point $\left({ }^{\circ} \mathrm{C}\right)$ & Fire point $\left({ }^{\circ} \mathrm{C}\right)$ & Viscosity (cst) \\
\hline Without adding & 20 & 159 & 165 & 23 \\
U2 + 5 gm & 25 & 160 & 175 & 18 \\
U2 + 10 gm & 32 & 166 & 177 & 17 \\
\hline
\end{tabular}

Table 4. Critical characteristics of FTO with and without adding activated carbon.

\begin{tabular}{ccccc}
\hline \multirow{2}{*}{ Parameters } & \multicolumn{3}{c}{ FTO Result } \\
\cline { 2 - 5 } & Breakdown voltage $(\mathrm{kV})$ & Flash Point $\left({ }^{\circ} \mathrm{C}\right)$ & Fire point $\left({ }^{\circ} \mathrm{C}\right)$ & Viscosity (cst) \\
\hline Without adding & 30 & 152 & 170 & 22 \\
FTO +5 gm & 29 & 155 & 175 & 21 \\
FTO $+10 \mathrm{gm}$ & 37 & 156 & 178 & 21 \\
\hline
\end{tabular}

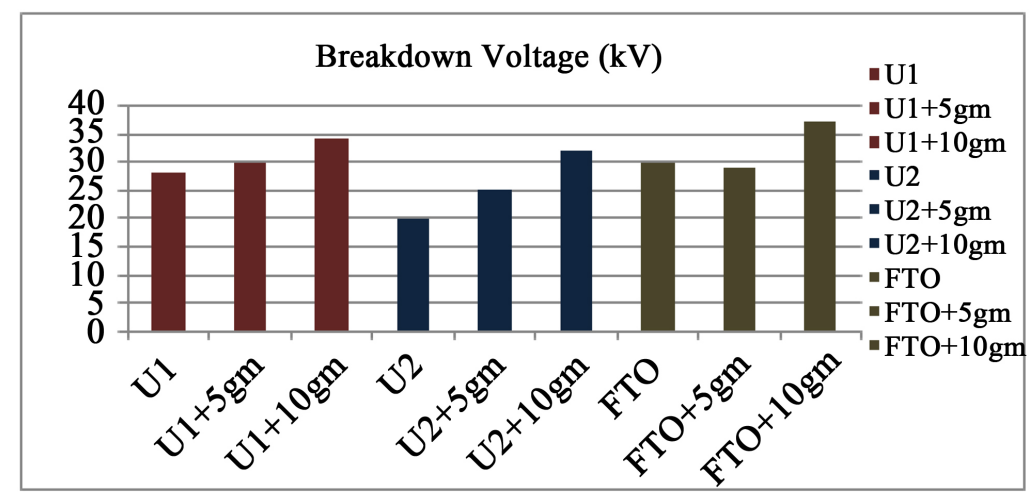

Figure 9. Breakdown voltage of insulating fluid with and without adding activated carbon.

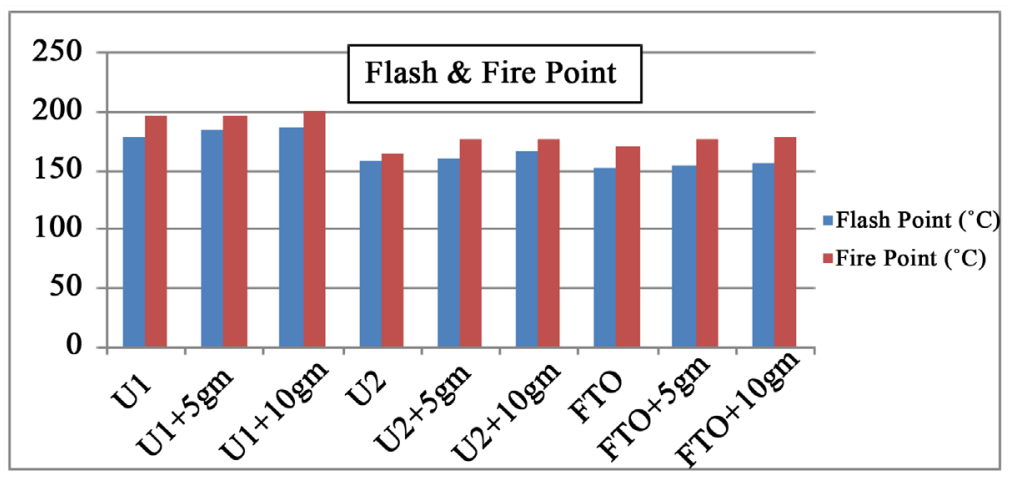

Figure 10. Flash point and fire point of insulating fluid with and without adding activated carbon. 


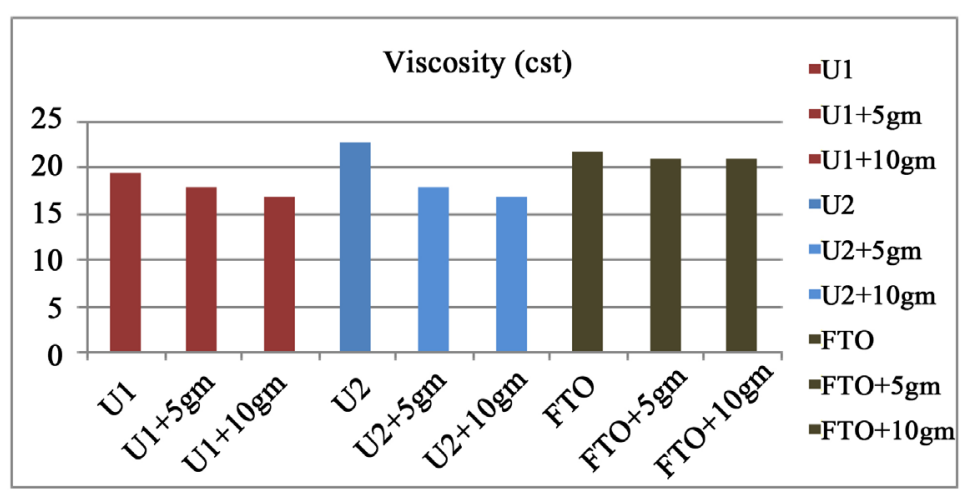

Figure 11. Viscosity of insulating fluid with and without adding activated carbon.

The FTO also increase the breakdown voltage by adding the activated carbon and it is shown in Table 4. The break down voltage of fresh oil is $30 \mathrm{kV}$ by adding $5 \mathrm{gm}$ of activated carbon with FTO the breakdown voltage is decreased to $29 \mathrm{kV}$ and by adding $10 \mathrm{gm}$ it is increased to $37 \mathrm{kV}$. Figure 9 depicts the improvement of breakdown voltage by adding activated carbon in aged as well as fresh oil.

Based on the obtained values, the used oil 1 with activated carbon shows continuous improvement which indicates the effectiveness of additives with oil. The used oil 2 with activated carbon also shows the continuous improvement but the breakdown voltage of used oil 2 with $5 \mathrm{gm}$ of activated carbon does not satisfy the standards this is mainly due to aging behavior (i.e.) used oil 1 is 20 hrs aged and used oil 2 is 40 hrs aged hence it requires more additives to enhance the degraded properties. The used oil 2 with $10 \mathrm{gm}$ of activated carbon gives higher value which indicates the effectiveness of additives with oil. In FTO the oil with $10 \mathrm{gm}$ of activated carbon proves the effectiveness of additives than 5 gm of activated carbon.

Tables 2-4 also describe about the flash point and fire point of aged and fresh mineral oil. It is inferred that the addition of activated carbon in aged and fresh mineral oil increase the flash point and fire point. In used oil 1 the flash and fire point is $178^{\circ} \mathrm{C} \& 195^{\circ} \mathrm{C}$. The used oil 1 with $5 \mathrm{gm}$ of activated carbon gives $183^{\circ} \mathrm{C} \mathrm{\&} 195^{\circ} \mathrm{C}$ whereas used oil 1 with 10 gm gives $187^{\circ} \mathrm{C} \& 200^{\circ} \mathrm{C}$. Similarly in used oil 2 the flash and fire point is $159^{\circ} \mathrm{C} \mathrm{\&}$ $165^{\circ} \mathrm{C}$. The used oil 2 with $5 \mathrm{gm}$ of activated carbon gives $160^{\circ} \mathrm{C} \& 175^{\circ} \mathrm{C}$ whereas used oil 2 with 10 gm gives $160^{\circ} \mathrm{C} \& 177^{\circ} \mathrm{C}$. In FTO the flash and fire point is $152^{\circ} \mathrm{C} \& 170^{\circ} \mathrm{C}$, FTO with 5 gm gives flash \& fire point as $155^{\circ} \mathrm{C} \& 175^{\circ} \mathrm{C}$ whereas FTO with $10 \mathrm{gm}$ provides flash \& fire point as $156^{\circ} \mathrm{C} \& 178^{\circ} \mathrm{C}$. Figure 10 graphically represents the flash point and fire point of insulating fluids with and without adding activated carbon. According to the values, the addition of activated carbon provides continuous improvement of flash and fire point.

Tables 2-4 explain about the viscosity of aged mineral oil and fresh mineral oil. In used oil 1 the viscosity is found to be 19.56 cst, by adding 5 gm of activated carbon the viscosity is reduced to 18 cst whereas by adding $10 \mathrm{gm}$ of activated carbon the viscosity reaches $17 \mathrm{cst}$. In used oil 2 the viscosity is measured to be 23 cst, by adding $5 \mathrm{gm}$ of activated carbon the viscosity is reduced to $18 \mathrm{cst}$ whereas by adding $10 \mathrm{gm}$ of activated carbon the viscosity reaches $17 \mathrm{cst}$. In case of FTO the viscosity is found to be $22 \mathrm{cst}$, by adding $5 \mathrm{gm}$ of activated carbon the viscosity is reduced to 21 cst whereas by adding 10 gm of activated carbon the viscosity reaches 21 cst. From this it is made clear that adding activated carbon reduce the viscosity which is mainly due to breaking of bonds by additives. Figure 11 provides the graphical representation of viscosity of insulating fluids with and without adding activated carbon.

Finally, it is made clear that the addition of activated carbon enhances the properties of aged mineral oil and fresh mineral oil. The critical characteristics measured by adding activated carbon are within the standards and so it is concluded that the degraded property of oil can be further improved by activated carbon that may reduce the oil scarcity in the near future.

\section{Conclusion}

Literally it is more and more important that the insulating fluid should provide better balance between high functional performances versus low environmental impact. In order to stumble on the recycle of insulating 
medium which has advanced properties, this work is investigating the different aged and fresh mineral oils by blending with additive compound such as activated carbon. Investigation suggests that the unsafe nature of the aged mineral oil can be regenerated by adding activated carbon. Periodic testing of additives present in the oil especially at higher temperature provides higher reliability at optimum cost, shelf life extension and stability. Proper servicing of aged mineral oil gives limitless life extension and free from formation of sludge and acidity that occurs due to oxidation. By keeping individual focus, the exploration explicates that the performance of oils with additives becomes superior and provides better properties. This paper offers the hands when scarcity occurs with mineral oil which has a renewable resource so this approach is intense in technical and environmental aspects. Hence the overall investigation concludes that the used and fresh oil blended with activated carbon is an appropriate support for transformer application.

\section{References}

[1] IEEE, Guide for Loading Mineral Oil Immersed Transformer (1995) Annexure I: Transformer Insulation Life, IEEE Standard C57.91.

[2] Rouse, T.O. (1998) "Mineral Oil in Transformers. IEEE Electrical Insulation Magazine, 14, 6-16. http://dx.doi.org/10.1109/57.675572

[3] Yuliastuti, E. (2010) Analysis of Dielectric Properties Comparison between Mineral Oil and Synthetic Ester Oil. Master of Science in Electrical Engineering Thesis, Delft University of Technology, Delft.

[4] Senthil Kumar, S., Willjuice Iruthayarajan, M. and Bakrutheen, M. (2014) Analysis of Vegetable Liquid Insulating Medium for Applications In High Voltage Transformers. IEEE International Conference on Science Engineering and Management Research, Chennai, 27-29 November 2014, 1-5.

[5] Ommen, T.V. (2003) Chemistry behind the Life of Transformer. Resonance, 8, 17-23.

[6] Hosier, L., Guushaa, A., Westenbrink, E.W., Rogers, C., Vaughan, A.S. and Swingler, S.G. (2011) Aging of Biodegradable Oils and Assessment of their Suitability for High Voltage Applications. IEEE Transactions on Dielectrics and Electrical Insulation, 18, 728-738. http://dx.doi.org/10.1109/TDEI.2011.5931059

[7] Young, W. (1998) Transformer Life Management-Condition Monitoring. Proceedings of the IEEE Colloquium Transformer Life Management, (Digest) IEEE Stevane, England, 1-4. http://dx.doi.org/10.1049/ic:19981006

[8] Okabe, S. and Kohtoh, M. (2010) Suppression of Increase in Electromagnetic Charging Tendency of Insulating Oil by Aging Used for Power Transformer Insulation. IEEE Transaction on Dielectrics and Electrical Insulation Magazine, 17, 473-480.

[9] Sierota, A. (1995) Electrical Insulating Oils Part I: Characterization and Pre-Treatment of New Transformer Oils. IEEE Transactions on Dielectrics and Electrical Insulation Magazine, 11, 8-20. http://dx.doi.org/10.1109/57.342040

[10] Schaut, A., Autru, S., De Rop, A. and Eeckhoudt, S. (2012) Effects of Irgament 30 as Additives in Transformer Oil. IEEE Transactions on Dielectrics and Electrical Insulation Magazine, 19, 175-180. http://dx.doi.org/10.1109/TDEI.2012.6148516

[11] AI-Zuhai, S. (2009) Using Activated Carbon from Waste Date-Pits as an Absorbent for Transformer Oil Regeneration. IEEE Transaction on Electrical Insulation Magazine, 25, 141-162.

[12] Lu Xl', (2010) The Study and Manufacture of the XD® Serials of Adsorbent and Its Efficiency of the Transformer Oil Treatment for a EHV Transformer. China International Conference on Electricity Distribution (CICED).

[13] Standard Test Method for Water in Insulating Liquids by Coulometric Karl Fischer Titration, ASTM D1533, 2012.

[14] Karthik, R. and Sree Renga Raja, T. (2012) Investigations of Transformer Oil Characteristics. IEEJ-TEE, 7, 369-374. http://dx.doi.org/10.1002/tee.21742

[15] Insulating Liquids-Determination of the Breakdown Voltage at Power Frequency-Test Method, IEC 60156, 3rd Edition, 2003-11.

[16] A Guide to Transformer Oil Analysis. I.A.R. Gray Transformer Chemistry Services.

[17] IEEE Guide for Loading Mineral-Oil-Immersed Transformers, IEEEC57.91-1995, 1995.

[18] Standard Test Methods for Flash Point by Pensky-Martens Closed Cup Tester, ASTM D 93, 2012.

[19] Standard Test Method for Kinematic Viscosity of Transparent and Opaque Liquids and Calculation of Dynamic Viscosity, ASTM D 445, 2011. 


\section{Submit or recommend next manuscript to SCIRP and we will provide best service for you:}

Accepting pre-submission inquiries through Email, Facebook, LinkedIn, Twitter, etc.

A wide selection of journals (inclusive of 9 subjects, more than 200 journals)

Providing 24-hour high-quality service

User-friendly online submission system

Fair and swift peer-review system

Efficient typesetting and proofreading procedure

Display of the result of downloads and visits, as well as the number of cited articles

Maximum dissemination of your research work

Submit your manuscript at: http://papersubmission.scirp.org/ 